\title{
Predicted impacts of climatic change on ant functional diversity and distributions in eastern North American forests
}

\section{Citation}

Del Toro, Israel, Rogério R. Silva, and Aaron M. Ellison. 2015. "Predicted Impacts of Climatic Change on Ant Functional Diversity and Distributions in Eastern North American Forests." Edited by Alan Andersen. Diversity Distrib. 21 (7) (April 13): 781-791. doi:10.1111/ddi.12331.

\section{Published Version}

doi:10.1111/ddi.12331

\section{Permanent link}

http://nrs.harvard.edu/urn-3:HUL.InstRepos:26507327

\section{Terms of Use}

This article was downloaded from Harvard University's DASH repository, and is made available under the terms and conditions applicable to Other Posted Material, as set forth at http:// nrs.harvard.edu/urn-3:HUL.InstRepos:dash.current.terms-of-use\#LAA

\section{Share Your Story}

The Harvard community has made this article openly available.

Please share how this access benefits you. Submit a story.

\section{Accessibility}


Predicted impacts of climatic change on ant functional diversity and distributions in eastern North American forests

Running Title: Climate change impacts on ant functional diversity

Article Type: Biodiversity Research Article

Authors:

Israel Del Toro ${ }^{1,2,3,4}$, Rogério R. Silva ${ }^{5}$, Aaron M. Ellison ${ }^{1,2}$

\section{Affiliations:}

${ }^{1}$ University of Massachusetts Amherst, Organismic and Evolutionary Biology, 611 North

Pleasant St. Amherst, Massachusetts 01003, USA

${ }^{2}$ Harvard Forest, 324 North Main St., Petersham Massachusetts, 01366, USA

${ }^{3}$ University of Copenhagen, Center for Macroecology Evolution and Climate, Universitetparken, 15 Copenhagen, 2100, Denmark

${ }^{4}$ The Jornada Basin Experimental Range, 2995 Knox St., Las Cruces New Mexico, 88003, USA

${ }^{5}$ Museu Paraense Emílio Goeldi, Coordenação de Ciências da Terra e Ecologia, Av. Magalhães

Barata, 376, CP 399, CEP 66040-170, Belém, Pará, Brazil. 


\begin{abstract}
:
Aims: Climatic change is expected to rearrange species assemblages and ultimately affect organism-mediated ecosystem processes. We focus on identifying patterns and relationships between common ant species (representing 99\% of total ant records) richness and functional diversity; model how these patterns may change at local and regional scales in future climatic conditions; and interpret how these changes might influence ant-mediated ecosystem processes.
\end{abstract}

Location: Forested ecosystems of eastern North America.

Methods: We used a previously published dataset to evaluate functional diversity at 67 sites in the eastern U.S, and quantified 14 taxonomic, morphometric, and natural history traits for 70 common ant species in the region. We used functional diversity metrics, functional groups, and species distribution modeling methods to address our aims. We used stacked species distribution models and stacked functional group models to predict species assemblages and functional richness at the 67 sites and at a regional scale for current and future climatic conditions.

Results: Species richness and functional diversity are positively correlated throughout the region. Under future climate scenarios, species richness and functional group richness were predicted to decrease in southern ecoregions and increase in northern ecoregions. This may be due to increased thermal stress for species in the southern extent of their ranges and increased habitat suitability in the northern ecoregions. Decomposers, arthropod community regulators and seed dispersers are forecast to be the most threatened ant functional groups.

Main Conclusions: Climate change will likely lead to major changes in ant species richness and functional group richness in the forests of the northeastern United States, and this may substantially alter ant-mediated ecosystem processes and services. 
Keywords: Climate Change, Environmental Gradients, Functional Diversity, Functional Group Models, Species Distribution Models

\section{Introduction:}

As species shift their distributions or change in abundances in response to climatic change, novel species assemblages are likely to occur (Williams \& Jackson, 2007; Bellard et al., 2012; Lurgi et al., 2012). These anticipated changes in biogeographic patterns may also result in changes to functional diversity and alterations to organism-mediated ecosystem services and processes (Montoya \& Raffaelli, 2010; Cardinale et al., 2011; Prather et al., 2012). However, the majority of biogeographic studies linking climatic change to changes in biodiversity patterns are species-centric: they typically consider the impact of climatic change on the distribution of one or more individual species. In contrast, the impacts of climatic change on functional roles of species or entire assemblages are rarely considered (McMahon et al., 2011).

Two methods are used commonly for assessing effects of climatic change on large-scale biodiversity patterns and to predict effects of climatic change on functional diversity: 1) empirical data collected along environmental gradients, where space is used as a surrogate of time (Lavergne et al., 2010; De Frenne et al., 2013) are used to asses species compositional changes with varying environmental conditions which may occur in future climates; 2) species distribution models that describe how suitable habitat for individual species is likely to change in response to future climatic conditions (Franklin, 2009, 2010) are used to infer potential suitable habitat for species in future climates. Both of these approaches have yielded valuable insights into how individual species or entire assemblages are likely to change under gradually changing climatic and environmental conditions (De Frenne et al., 2013). However, it remains difficult to 
evaluate how changes in species composition will translate to changes in functional diversity: the value and range of those species traits that influence ecosystem functioning (Tilman, 2001).

There are many examples of ecosystem services and processes being mediated by a wide variety of taxonomic groups (e.g., plants, birds, beetles, ants). Among these, the $\approx 13,000$ species of ants occur in nearly all habitats on Earth (Ward, 2010), are taxonomically well-understood at the genus level, have well documented natural history traits, and are responsible for multiple ecosystem services and processes (Del Toro et al., 2012). Ants, therefore, are an ideal taxon to use in large-scale, biogeographic studies that aim to evaluate and predict effects of climatic change on functional diversity and ecosystem processes because their diversity is well documented (and manageable compared to other arthropod groups) and their responses to changing environments are increasingly being studied.

Ant functional diversity has often been viewed in terms of classifying ants into functional groups that categorize species based on taxonomic relatedness, habitat preferences (or environmental tolerance), and their behavioral interactions with other species in their communities (Andersen, 1995; Ellison, 2012). However, recent advances in understanding functional diversity integrate natural history information with other quantitative data to characterize functional diversity and classify organisms into more informative functional groups (Laliberté \& Legendre, 2010; Arnan et al., 2012; Silva \& Brandão, 2014). Here, we use this integrated approach to develop and use a classification of ant functional diversity that is defined both relative to a species or group of species roles and to their contributions to ecosystem services and processes.

First we develop a new functional-group classification for the common ants of eastern North America. We then use this functional classification to assess how ant species richness and 
functional diversity are likely to be affected by regional climatic change. We identify functional diversity patterns in seven level II ecoregions (Wiken et al., 2011) and ask how species richness and functional diversity in these ecoregions will respond to future climates.

\section{Methods:}

Study region and ant assemblage data

We used data from a previous study in which ants were sampled systematically along a latitudinal gradient at 67 sites in the eastern United States (Del Toro, 2013). The extent of this study covered seven of the North American Level II ecoregions: 1) Soft Wood Shield, 2) Mixed Wood Shield, 3) Atlantic Highlands, 4) Mixed Wood Plains, 5) Southeast USA Plains, 6) Appalachian Forests and 7) Southeast USA Coastal Plains (boundaries plotted on figures 5-8). Although Del Toro (2013) identified 92 species at the 67 sites, we used only those species for which we have distribution, abundance, and some trait data $(\mathrm{n}=70)$. Abundance data were extracted from the site $\times$ species matrix of the 2010 study (data available online: http://www.plosone.org; DOI: 10.1371/journal.pone.0067973). We used the number of incidences - i.e., the number of pitfall traps in which a species was collected - as our measure of abundance and not the number of individual ants as these results were not significantly different (Del Toro, 2013). Each incidence likely corresponded to an independent nest (a unit of abundance for ants as interpreted by colony density: Gotelli et al., 2011) because traps were separated by $10 \mathrm{~m}$ - more than the average foraging distance of a single colony in eastern North American forests. In this system only a very small proportion of ant species ( 2\%) have been observed to have foraging distances greater 2 meters (Personal communication with K. Stuble). In the 2010 we observed a total of 3721 total species incidences, of those incidences 3673 ( $99 \%)$ correspond to the species in this study, suggesting that this study considers the species 
providing the overwhelming majority of ant-mediated ecosystem services. The maximum abundance per species per site $=40$, because there were a total of 40 pitfall traps at each site. Trait data, functional groups and functional diversity analyses:

To classify ants according to functional traits, we used two taxonomic, three morphometric, and nine natural history traits for 70 species from eastern North America. The morphometric traits were measured in the laboratory and the natural history traits were gathered from various published and online sources. Following principles in Petchey and Gaston (2006), we focused on traits that directly influence major ecosystem processes mediated by ants, including: 1) soil movement, 2) decomposition, 3) seed dispersal, and 4) invertebrate and plant community regulation. Measures for each trait were derived from three main sources: Ellison et al. (2012), www.antweb.org, and www.antwiki.org.

We focus on these four major ecosystem processes as these are all well documented in the literature and can have major ecosystem-level consequences. Ants are often referred to as ecosystem engineers because they modify soil nutrients and properties (Frouz \& Jilková, 2008), typically these modifications are caused by medium to large body sized, soil dwelling ants. Even though ants may not be directly responsible for decomposition, ants mediate and in some cases facilitate the decomposition process (e.g. Wardle et al., 2011) by breaking down large organic particles, either by nesting in wood and leaf litter, foraging for vegetation or consuming larger food particles. Ant seed dispersal, or myrmecochory, is a widespread ecosystem service mediated by ants across multiple lineages and geographic regions (Lengyel et al., 2010) including eastern temperate forests where it may be more common or have a greater effect (Del Toro et al. 2012). Finally some species of ants regulate the community structure of other ants and 
invertebrates through predation, parasitism, and mutualistic relationships (see various examples reviewed in Del Toro et al., 2012).

We used subfamily and genus (the two taxonomic traits) as surrogates for phylogenetic traits because the generic-level taxonomy and phylogeny for the species in this study are well resolved (Moreau et al., 2006). Taxonomic traits also help to categorize a species' functional role, as species within the same genera or subfamilies often have similar niches or functional roles in ecosystems (Webb et al., 2002).

The three morphometric traits we used - head length, relative eye length, and leg length relative to body size - reflect body size (which is correlated with head length), foraging capacity, foraging period, and modes of resource acquisition (Bihn et al., 2010). For 3-10 pinned and mounted individuals of each species, we measured head length, eye length, and femur length at $50 \times$ magnification using a calibrated ocular micrometer attached to Leica microscope. We used the mean for each trait as the trait value for each species. We only measured minor workers to avoid any confounding factors from disproportionately large major workers in polymorphic species.

Colony size often is well correlated with the amount of soil moved by a species (Mikheyev \& Tschinkel, 2004) and accounts for the potential impact that large colonies can have on mediating ecosystem processes. Colony size for each species was categorized into four categories, small (<100 workers); medium (100-1000 workers); large (1000-5000 workers); and very large colonies ( $>5000$ workers).

Secondly, we categorized the feeding preferences of each species as: 1) omnivores; 2) predators; 3) granivores; or 4) honeydew (based on Ellison et al. 2012). Most species were categorized as omnivores, which play key roles in mediating decomposition of animal carcasses. 
The few predators and granivores play significant roles in regulating community structure of other invertebrates or plant communities (see review in Del Toro et al., 2012). Honeydew feeders also may form mutualistic relationships with hemipterans (Way, 1963).

For natural history traits which relate to habitat preferences, we classified each species according to its general biogeographic affinity based on available occurrence records: 1) widespread (distributed throughout the entire extent of the study region), 2) warm climate (distributed only in the southern extent of the study region), or 3) cold climate (distributed only in the northern extent of the study region). We then categorized the primary and secondary habitat where each species is commonly found. Primary habitats included: 1) bogs, 2) edge habitat, 3) open habitat, 4) conifer forests, 5) deciduous forests, 6) forests (either conifer or deciduous), or 7) subterranean. Secondary habitat associations were: 1) wet soils, 2) mix of litter and grass, 3) exclusively grassy areas, 4) exclusively leaf litter, 5) rocky soils, or 6) sandy soils. For the last natural history habitat trait, we categorized species according to whether they nest in: 1) soil, 2) wood, 3) grass, or 4) acorns. These nesting preferences also are related to whether a species moves soil, decomposes wood, or disperses seeds.

Last, we identified natural history traits related to interspecific interactions with other ants. For all of the species, we noted whether it was known to be a social parasite or a slavemaking species. For 33 species, we also were able to classify them based on their behavioral interactions with other ants: 1) competitive dominant, 2) submissive, or 3) neutral. These data were derived from previous field observations (Del Toro et al., 2013) and laboratory trials (Wittman \& Gotelli, 2011). For the remaining 37 species the behavioral traits in the matrix were left blank. 
We used the FD package version 1.0 (Laliberté \& Legendre, 2010) in R version 3.0.3 (R Core Team 2014) to calculate functional diversity indices and designate functional group classifications. Specifically we used the “dbFD” function to calculate Rao’s Q and FEve. Rao’s $\mathrm{Q}$ is the appropriate measure for functional diversity in this study as this metric takes into account the sum of the pairwise distances between this suite of commonly distributed species weighted by their relative abundances throughout our sampling sites (Rao, 1982), and FEve is a metric of functional evenness that measures the regularity of spacing between species in traits space as well as the evenness in the distribution of species abundances (Villéger et al., 2008). We also used this function to visually evaluate a dendrogram that grouped all of the species into functional groups based on trait similarities based on the functional dispersion index "FDis" and the "ward" clustering method. The "ward" method aims to find the minimum number of spherical clusters which we identified as having a cluster dendrogram height of $\leq 1$. The "FDis" index is the multivariate analogue of the weighted mean absolute deviation (Laliberte \& Legendre, 2010). We then grouped the species into ten functional groups based on the similarity of their traits (Table 1; see Appendix S1 for data and dendrogram Figure S2).

\section{Species Distribution and Functional Group Models}

To develop species distribution models (SDMs) we geo-referenced data from 10 major entomological collections in the region (See Appendix S3 collections list and number of records). We gathered 11,985 point observations for the 70 species throughout the eastern United States. Unique site observations ranged from 649 for Camponotus pennsylvanicus to 23 for Pheidole pilifera. (See Appendix S3 Figure S4). The data and R code are archived online in the Harvard Forest Data Archives http://harvardforest.fas.harvard.edu/data-archive. 
To create a consensus distribution maps for each species, we used four different modeling algorithms to develop SDMs for each species, Generalized Linear Models (GLMs), Generalized Additive Models (GAMs), MaxEnt, and Boosted Regression Trees (BRTs). To predict species occurrences, we used data extracted from the eight least correlated and biologically informative of the 19 BioClim variables (annual mean temperature, mean diurnal range, isothermality, maximum temperature of the warmest month, minimum temperature of the coldest month, annual precipitation, precipitation seasonality, precipitation of the driest quarter) (Hijmans et al., 2005). For modeling and prediction, we used the R packages: 'dismo' v.1.0-5 (Hijmans et al., 2014), 'raster' v.2.3-12 (Hijmans, 2014), and 'SDMTools' v1.1-221.0 (VanDerWal et al., 2014). We accounted for sampling bias by creating a sampling bias grid surface as done by Fitzpatrick et al. (2013). We generated a sampling bias surface, by summing the number of ant occurrence records found within each 2-arc-minute grid cell and then extrapolated these data across the study region using kernel density estimation as implemented in the sm package (Bowman \& Azzalini, 2014). We then created 10,000 random background points weighted by the sampling bias surface (Elith et al., 2010) which used to evaluate the accuracy of the models.

For each SDM we partitioned the data into a $75-25 \%$ split where $75 \%$ of the data were used for model building and $25 \%$ of the data were used to evaluate the model accuracy. For each modeling algorithm we selected a conservative threshold, "specific-sensitivity (see Hernandez et al., 2006; Bean et al., 2012). The binary maps were then overlaid on each other to calculate a consensus map which reflect the potential occurrences of a species and not abundances. Our consensus map of the distribution of each species was determined if at least three out of four SDMs predicted the occurrence of the species at any map pixel. To build the functional group models (FGMs) we stacked the binary predictions of all species within each functional group and 
mapped their cumulative distribution. To scale our findings to a basic community level analysis we used stacked species distribution models (S-SDMs) to estimate species richness throughout the extent of the study region. We repeated this with the functional group models to estimate functional group richness.

To predict changes in future species distributions, we projected each model output to 2050 and 2070 under four future climate scenarios (RCP 2.6,4.5,6.0 and 8.5) (IPCC 2013) using the Hadley Center Coupled Model version 3 (HADCM3), applied the same "specific-sensitivity" threshold, and repeated the stacking method to derive a consensus map of the most likely future species distribution. We identified the total amount of range contraction and expansion for each species by calculating the difference between their current modeled and future distribution. We repeated this process for functional groups by overlaying the SDMs of the species in each functional group and creating a functional group distribution map for future climatic conditions (S5). We used S-SDMs and stacked functional group modes (S-FGMs) to predict richness and functional group richness at the 67 sampled sites. The stacked models were obtained by summing the binary distribution maps.

We extracted the predicted values of species and functional group richness from the future distribution projections and evaluated how local richness patterns might change in future climates by regressing richness values against three years (2000 (historical range), 2050, and 2070) using the four climate scenarios mentioned above. We then plotted the slopes (regression coefficients) against latitude to identify sites where changes in species richness and functional group richness might be the greatest. The values of these slopes correspond to the change in number of species or functional groups per year at each of the 67 sites. A positive value indicates 
a gain in species or functional group richness and a negative value indicates a loss of species or functional group richness (Figures $3 \& 4$ ).

\section{$\underline{\text { Results: }}$}

Relationships between local observed species richness and functional diversity

The best-fit quadratic regressions suggest that as species richness increased, functional diversity and the number of functional groups also increased in the 67 sampled sites, (Figure 1A and 1B; Adjusted R-sq.= 0.44 and 0.49 respectively, p-value $<0.0001)$. FEve ranged from 0.55 to 0.90 suggesting that functional evenness was comparable between the sites. However, FEve was not correlated with species richness or with latitude (Adjusted R-sq<0.01, p>0.05). Species distribution models had Area under the ROC curve (AUC) values ranging from 0.99 to 0.72 ; any AUC values $<0.5$ suggest that the models are yielding predictions which are better than a completely random distribution. In most cases MaxEnt and BRT produced the most accurate models and GAMs tended to preform better than GLMs (See S4 for detailed outputs of AUC values).

Stacked SDMs overestimated observed species richness by as much as 55\% at nearly every site (Fig. 2A) and the relationship between observed richness and predicted richness (from S-SDMs) variables, although statistically significant, was very weak (Adjusted R-sq=0.08, pvalue $=0.012$ ). In contrast, the relationship between observed functional group richness and predicted functional group richness at the 67 sites was much stronger (Adjusted R-sq=0.53, pvalue $<0.001)$ and over-prediction was only $\approx 10 \%$. The best-fit regression line better approximated the 1:1 ratio line suggesting that S-FGMs might be useful in predicting functional diversity patterns at large geographic scales (Fig. 2B). 
Predicted changes in local species and functional group richness

Of the 67 sites sampled, those in the southernmost extent of the study and along coastal regions tended to have higher species richness than sites in northern latitudes or higher elevations (Del Toro, 2013). The southernmost sites were predicted to experience significant species losses under future climatic conditions, whereas sites in the north were forecast gain species (Fig. 3, Table 2). The most extreme species richness declines in the southern sites was forecast to have up to $85 \%$ of species loss, but in the northern sites, some sites were forecasted to have a threefold increase in richness (Fig. 3, Table 2). Functional diversity was largely projected to stay the same at many sites but some northern sites were forecast to see a two-fold increase in functional group richness in future climates (Figure 4).

\section{Predicted changes in regional species and functional group richness}

By 2050, the S-SDMs predicted that species richness would increase in three northern ecoregions (i.e., Soft Wood Shield, Mixed Wood Shield and Atlantic Highlands). However, in the Mixed Wood Plains, only regions north of $\sim 43^{\circ} \mathrm{N}$ and along the Atlantic coast were expected to increase in species richness. South of $\sim 43^{\circ} \mathrm{N}$ and in the interior, species richness was expected to decrease. In Appalachian Forests, species richness was expected to decrease widely, except in regions where elevations exceeded 500m. The largest predicted species richness losses were expected to occur in the Southeast Coastal Plains and the Southeast USA Plains. These trends were similar across all climate scenarios (Fig. 5A-D). By 2070 the patterns of changes of species richness were similar to those of 2050, but under the most extreme scenarios (RCP 4.5, 6.0, and 
8.5) the high elevation areas of Appalachian Forests and the Mixed Wood Plains (north of $45^{\circ} \mathrm{N}$ ) also were forecast to decrease in species richness (Fig 6 A-D).

Like species richness, functional group richness was forecast to increase in most ecoregions north of $45^{\circ} \mathrm{N}$ latitude and to decrease in most ecoregions south of $\sim 42^{\circ} \mathrm{N}$ (Fig.6 AD). The Atlantic Highlands ecoregion was forecast to experience the highest increase in functional group richness by 2050 and 2070 (Fig.6-7). In contrast the Southeast USA Coastal Plains were forecast to experience the largest functional group richness declines (Fig.6-7). There was region of relatively low change in functional group richness in southern New England and the northern Mid-Atlantic states, but even this region was forecast to see large reductions in functional group richness by 2070 (Fig.7A-D).

All functional groups were forecast to increase their range size under future climate scenarios. Soil movers and seed dispersers showed the largest range increases $(\geq 100 \%$ increase in range sizes). Invertebrate community regulators showed the lowest change of range size and three of four scenarios predicted a range contraction of $\sim 2 \%$. The remaining functional groups showed range expansions ranging from $20 \%$ to $60 \%$ (Fig. 9).

\section{Discussion:}

We have developed and presented one of the first approaches to understanding the spatial distribution of functional diversity and functional groups by using S-FGMs. The majority of sites we studied in eastern North America (80\%) have six or more functional groups at each site and functional evenness (FEve) was not correlated with richness or latitude, suggesting that functional roles of ants as soil movers, decomposers, seed dispersers and community regulators 
are important and widespread throughout eastern North America. Furthermore, by using SFGMs, it appears to be possible to apply standard methods of spatial analyses to forecast future distributions and assemblages of functional groups at both regional and local scales. There is a growing number of studies that use biologically informative traits in ants to better understand patterns of functional diversity, trophic relationships and habitat use (e.g. Gibb et. al., 2015). When biologically informative trait data is coupled with analyses like those presented here we can begin to better understand the impacts of climatic change on ant functional diversity at large spatial scales.

In the region that we studied - the eastern United States - functional diversity (Rao's Q) and species richness are correlated. As species richness increases, functional diversity also tends to increase, as do the number of functional groups, a pattern that is common in nature and contributes to the understanding of how communities assemble by highlighting patterns of niche filtering (Mouchet et al., 2010). We note that the best fit correlations between species richness and Rao's Q and the number of functional groups is a quadratic function, which is likely driven by the limited number of species and functional groups that can occupy any of the study sites and the overall sampling coverage at any given site. A detailed summary of sampling coverage at these sites is discussed in Del Toro (2013). The forecast changes in species and functional group richness ultimately may translate into changes in the importance or prevalence of the primary functional roles of ants throughout Eastern North America (see also Andersen, 1997; Crist, 2009), but is more clearly tied to specific ant-mediated ecosystem processes in this work. In addition, our results suggest that S-FGMs have less over-prediction problems than S-SDMs; the over-prediction issues of the latter have been discussed elsewhere (Mateo et al., 2012). This 
trend should be studied in other ecosystems - especially those with extremely high species richness and functional diversity - to better understand the generality of this pattern.

In some situations, regions or sites with the highest species richness could also be the most insulated from changing environments due to functional redundancy within the system. As a result, there would have to be very large changes in species diversity to alter organismmediated ecosystem processes substantially (Cardinale et al., 2011). Among ants, our data suggest that the highest species diversity and functional diversity both occur in the warmer (southern) ecoregions of eastern North America. These are the same ecoregions that we forecast to see large changes in species richness and functional group richness under future climatic scenarios. Changes in species richness and functional diversity in the southern ecoregions do not necessarily translate to a total loss of ants from these ecosystems, it is more likely that some species currently found in the Southeastern Plains and Southern Tropical Coastal Plains will shift their ranges north and fill the niches and ecological roles played by the historical ant communities. The southeastern United States has $\sim 330$ species of ants, many of their ranges expand in the southern extent of our study region. It is unlikely that all species in the southeast will expend their ranges into the northeastern United States but as many as 200 species may be able to track changes in temperature and precipitation, thus resulting in a range expansions (pers. comm. Joe MacGown). Fitzpatrick et al. (2011) predicts that approximately half of the genera in the southeast may contract their ranges in the southeastern U.S. and expand into regions in northern North America (assuming full dispersal scenarios). Additionally, Lessard et al. (2007) sampled ant communities along an elevation gradient in the Great Smoky Mountains National Park in the southeastern U.S. and found that species richness decreased with increasing elevation. If these results were to be interpreted as prediction of future changes in richness due to 
changes in local temperatures, we can forecast that as many as $50 \%$ of species in the southeastern U.S. may be capable of tracking changes in climate and thus expand their current ranges into the southern extent of our study. Future work should specifically address how ants of the southeastern forests can be expected to respond to regional climatic change. In contrast the northern ecoregions are likely to experience gains in species and functional group richness. These changes imply the expansion of ranges of several species within each functional group into new suitable habitat, and ultimately can translate into the preservation of functional diversity and the ecosystem processes mediated by ants across all functional groups in northern ecoregions.

Our study has some limitations, first is the use of only a subset of species known to occur in eastern North American ecosystems. Our study focuses on 70 of 92 previously documented species, but the species in this study are typically the most commonly collected and abundant species of the region. A more detailed account of the effects of climate change on the rare species of the region is necessary as these may be species of conservation concern. We suggest that changes in rare species abundances may not be different in future climates as rare species tend to remain rare even in changing environments (Kunin \& Gaston, 1997). Another limitation of this study is that our traits dataset remains incomplete, as data on natural history traits, abundances and distributions become available the functional group classification of the species studied here are subject to change. In this study the functional group classification remains robust enough to allow for future modifications. Our aim here is to present a first step towards a new approach of classification of ants based on their applied functional roles in temperate forested ecosystems by making use of both quantitative and qualitative datasets. We also note that the patterns of over-prediction persist in our analyses (albeit significantly reduced when 
using S-FGMs). We urge that a cautious interpretation of our projections be implemented due to uncertainty in the models. Over-prediction species richness in S-SDM analyses is not uncommon and does not indicate poorly preforming distribution models. Instead this overprediction is due to additional factors like biotic interactions and microhabitat suitability (which were not included in our analyses) influencing the persistence of a species in any given locality. Mechanistic SDMs and finer resolution environmental predictors should improve site-level prediction of species and functional group richness. Finally, we note that all of our predictions reflect a "full dispersal scenario," which assumes that none of the species are limited by their dispersal capacities and are able to track habitat suitability in a rapidly changing climate (but see Fitzpatrick et al., 2011).

It is important to note that changes in functional group richness may not be apparent from simply looking at the presence/absence maps of each functional group (Appendix S5). Although changes in species richness are likely to result in similar changes to functional diversity (see also Fitzpatrick et al., 2011), the persistence of all functional groups at any given point appears to be driven largely by a smaller subset of species. If high functional redundancy occurs in a region and a few species in different functional groups persist through climatic changes, then functional diversity will be preserved. If not, then functional diversity can be lost. Of particular concern are wood decomposers (functional group 2), seed dispersers (7) and leaf-litter community regulators (10). Wood decomposers and leaf litter community regulators are forecast to have large species range-size contractions; the persistence of these functional groups, especially in the southern ecoregions, will be dependent on the response to climatic change of one or two species within their functional group. For seed dispersers (specifically their function as myrmecochores), not only does the persistence of their function depend on whether particular species keep up with 
changes in habitat suitability (which applies to all functional groups), but also necessitates the persistence of their associated myrmecochorous plants to track changing climates in similar ways (Stuble et al., 2014).

\section{Conclusions:}

In eastern North America, ant species richness and functional diversity are correlated, and using S-FGMs can be useful in predicting faunal assemblages and functional roles of ants at large spatial scales. Under different scenarios of future environmental conditions, ant species richness and functional diversity are forecast to decrease in southern ecoregions and increase in the northern ecoregions. Climatic change is not predicted to affect all species and functional groups equally, with some functional groups like decomposers, seed dispersers and community regulators being especially vulnerable to changing climates. Future work should continue to track changes throughout the study region to track the effects of climatic change on the region and test the predictions of our models.

\section{Acknowledgements:}

We thank Alan Andersen, Bethany Bradley, Jack Finn, and Nicholas Gotelli and two anonymous reviewers for their comments of earlier drafts of this manuscript. Funding assistance for traveling to regional entomological collections was provided by the American Museum of Natural History collections study grant, and the Academy of Natural Sciences Jessup Fellowship. IDT was supported by the NEAGEP Fellowship. AME was supported by grants from the US Department of Energy (DE-FG02-08ER64510) and US National Science Foundation (11-36646). R.R. Silva was supported by FAPESP (Proc. No. 2010/51194-1 and 2010/20570-8). 


\section{$\underline{\text { References: }}$}

Andersen A.N. (1995) A Classification of Australian Ant Communities, Based on Functional Groups Which Parallel Plant Life-Forms in Relation to Stress and Disturbance. Journal of Biogeography, 22, 15-29.

Andersen A.N. (1997) Functional groups and patterns of organization in North American ant communities: a comparison with Australia. Journal of Biogeography, 24, 433-460.

Arnan, X., Cerdá, X., \& Retana, J. 2012. Distinctive life traits and distribution along environmental gradients of dominant and subordinate Mediterranean ant species. Oecologia, 170, 489-500.

Bean W.T., Stafford R., \& Brashares J.S. (2012) The effects of small sample size and sample bias on threshold selection and accuracy assessment of species distribution models. Ecography, 35, 250-258.

Bellard C., Bertelsmeier C., Leadley P., Thuiller W., \& Courchamp F. (2012) Impacts of climate change on the future of biodiversity. Ecology Letters, 15, 365-377.

Bihn J.H., Gebauer G., \& Brandl R. (2010) Loss of functional diversity of ant assemblages in secondary tropical forests. Ecology, 91, 782-792.

Bowman A.W. \& Azzalini A. (2014) R package "sm": nonparametric smoothing methods. (version 2.2-5.4) URL http://azzalini.stat.unipd.it/Book_sm.

Cardinale B.J., Matulich K.L., Hooper D.U., Byrnes J.E., Duffy E., Gamfeldt L., Balvanera P., O'Connor M.I., \& Gonzalez A. (2011) The functional role of producer diversity in ecosystems. American Journal of Botany, 98, 572-592. 
Crist T.O. (2009) Biodiversity, species interactions, and functional roles of ants ( Hymenoptera: Formicidae ) in fragmented landscapes : a review. Myrmecological News, 12, 3-13.

De Frenne P., Graae B.J., Rodríguez-Sánchez F., Kolb A., Chabrerie O., Decocq G., De Kort H., De Schrijver A., Diekmann M., Eriksson O., Gruwez R., Hermy M., Lenoir J., Plue J., Coomes D. a., \& Verheyen K. (2013) Latitudinal gradients as natural laboratories to infer species' responses to temperature. Journal of Ecology, 101, 784-795.

Del Toro I. (2013) Diversity of Eastern North American ant communities along environmental gradients. PloS One, 8, e67973.

Del Toro I., Ribbons R.R., \& Pelini S.L. (2012) The little things that run the world revisited: a review of ant-mediated ecosystem services and disservices (Hymenoptera: Formicidae). Myrmecological News, 17, 133-146.

Del Toro I., Towle K., Morrison D.N., \& Pelini S.L. (2013) Community Structure and Ecological and Behavioral Traits of Ants (Hymenoptera: Formicidae) in Massachusetts Open and Forested Habitats. Northeastern Naturalist, 20, 103-114.

Elith J., Kearney M., \& Phillips S. (2010) The art of modelling range-shifting species. Methods in Ecology and Evolution, 1, 330-342.

Ellison A.M. (2012) Out of Oz : opportunities and challenges for using ants (Hymenoptera : Formicidae) as biological indicators in north-temperate cold biomes. Myrmecological News, 17, 105-119. 
Ellison A.M., Gotelli N.J., Farnsworth E.J., \& Alpert G.D. (2012) A Field Guide to the Ants of New England. Yale University Press, 396 pp.

Fitzpatrick M.C., Sanders N.J., Ferrier S., Longino J.T., Weiser M.D., \& Dunn R. (2011)

Forecasting the future of biodiversity: a test of single- and multi-species models for ants in North America. Ecography, 34, 836-847.

Fitzpatrick M.C.F., Gotelli N.J., \& Ellison A.M. (2013) MaxEnt versus MaxLike : empirical comparisons with ant species distributions. Ecosphere, $\mathbf{4}$, art55.

Franklin J. (2009) Mapping species distributions: spatial inference and prediction. Cambridge University Press, Cambridge, United Kingdom and New York, USA, 338 pp.

Franklin J. (2010) Moving beyond static species distribution models in support of conservation biogeography. Diversity and Distributions, 16, 321-330.

Frouz J. \& Jilková V. (2008) The effect of ants on soil properties and processes (Hymenoptera: Formicidae). Myrmecological News, 11, 191-199.

Gibb H., Stoklosa J., Warton D.I., Brown A.M., Andrew N.R., \& Cunningham S.A. (2015) Does morphology predict trophic position and habitat use of ant species and assemblages? Oecologia, 177, 519-531.

Gotelli N.J., Ellison a. M., Dunn R.R., \& Sanders N.J. (2011) Counting ants (Hymenoptera: Formicidae): biodiversity sampling and statistical analysis for myrmecologists. Myrmecological News, 15, 13-19. 
Hernandez P.A., Graham C.H., Master L.L., Albert D.L., \& The A.D.L. (2006) The effect of sample size and species characteristics on performance of different species distribution modeling methods. Ecography, 29, 773-785.

Hijmans, R.J., Phillips S., Leathwick J., \& Elith J. (2014). dismo: Species distribution modeling. $\mathrm{R}$ package version 1.0-5. http://CRAN.R-project.org/package=dismo

Hijmans R.J. (2014). raster: Geographic data analysis and modeling. R package version 2.3-12. http://CRAN.R-project.org/package=raster

Hijmans R.J., Cameron S.E., Parra J.L., Jones P.G., \& Jarvis A. (2005) Very high resolution interpolated climate surfaces for global land areas. International Journal of Climatology, 25, 1965-1978.

IPCC (2013) Climate Change 2013: The Physical Science Basis. Contribution of Working Group I to the Fifth Assessment Report (AR5) of the Intergovernmental Panel on Climate Change. Cambridge University Press, Cambridge, United Kingdom and New York, USA, 1535 pp.

Kunin W.E. \& Gaston K.J. (1997) The biology of rarity: Causes and consequences of rarecommon differences. Springer, Netherlands, $280 \mathrm{pp}$.

Laliberté E. \& Legendre P. (2010) A distance-based framework for measuring functional diversity from multiple traits. Ecology, 91, 299-305.

Lavergne S., Mouquet N., Thuiller W., \& Ronce O. (2010) Biodiversity and climate change: integrating evolutionary and ecological responses of species and communities. Annual Review of Ecology, Evolution, and Systematics, 41, 321-350. 
Lengyel S., Gove A.D., Latimer A.M., Majer J.D., \& Dunn R.R. (2010) Convergent evolution of seed dispersal by ants, and phylogeny and biogeography in flowering plants: A global survey. Perspectives in Plant Ecology, Evolution and Systematics, 12, 43-55.

Lessard J.P., Dunn R.R., Parker C.R., \& Sanders N.J. (2007) Rarity and diversity in forest ant assemblages of Great Smoky Mountains National Park. Southeastern Naturalist, 6, 215228.

Lurgi M., Lopez B.C., \& Montoya J.M. (2012) Novel communities from climate change. Philosophical Transactions of the Royal Society B: Biological Sciences, 367, 2913-2922.

Mateo R.G., Felicisimo A.M., Pottier J., Guisan A., \& Munoz J. (2012) Do stacked species distribution models reflect altitudinal diversity patterns? PLoS ONE, 7, e32586.

McMahon S.M., Harrison S.P., Armbruster W.S., Bartlein P.J., Beale C.M., Edwards M.E., Kattge J., Midgley G., Morin X., \& Prentice I.C. (2011) Improving assessment and modelling of climate change impacts on global terrestrial biodiversity. Trends in Ecology and Evolution, 26, 249-259.

Mikheyev A.S. \& Tschinkel W.R. (2004) Nest architecture of the ant Formica pallidefulva: structure, costs and rules of excavation. Insectes Sociaux, 51, 30-36.

Montoya J.M. \& Raffaelli D. (2010) Climate change, biotic interactions and ecosystem services. Philosophical transactions of the Royal Society of London. Series B, Biological Sciences, 365, 2013-2018. 
Moreau C.S., Bell C.D., Vila R., Archibald S.B., \& Pierce N.E. (2006) Phylogeny of the ants: diversification in the age of angiosperms. Science, 312, 101-104.

Mouchet M.A., Villéger S., Mason N.W.H., \& Mouillot D. (2010) Functional diversity measures: An overview of their redundancy and their ability to discriminate community assembly rules. Functional Ecology, 24, 867-876.

Petchey O.L. \& Gaston K.J. (2006) Functional diversity: Back to basics and looking forward. Ecology Letters, 9, 741-758.

Prather C.M., L Pelini S., Laws A., Rivest E., Woltz M., Bloch C.P., Toro I. Del, Ho C.-K., Kominoski J., Scott Newbold T.A., Parsons S., \& Joern A. (2012) Invertebrates, ecosystem services and climate change. Biological Reviews, 88, 327-348.

R Core Team R. (2014) R: A Language and Environment for Statistical Computing. $R$ Foundation for Statistical Computing. Vienna, Austria (http://www.R-project.org/).

Rao C.R. (1982) Diversity and dissimilarity coefficients: A unified approach. Theoretical Population Biology, 21, 24-43.

Silva, R.R. \& Brandão, C.R.F. 2014. Ecosystem-wide morphological structure of leaf-litter ant communities along a tropical latitudinal gradient. PLoS One, 9, e93049.

Stuble K.L., Patterson C.M., Rodriguez-Cabal M.A., Ribbons R.R., Dunn R.R., \& Sanders N.J. (2014) Ant-mediated seed dispersal in a warmed world. PeerJ, 2, e286.

Tilman D. (2001) Functional diversity. Encyclopedia of Biodiversity, 3, 109-120. 
VanDerWal J., Falconi L., Januchowski S., Shoo L., \& Storlie C. (2014). SDMTools: Species Distribution Modelling Tools: Tools for processing data associated with species distribution modelling exercises. R package version 1.1-221. http://CRAN.Rproject.org/package=SDMTools.

Villéger S., Mason N.W.H., \& Mouillot D. (2008) New multidimensional functional diversity indices for a multifaceted framework in functional ecology. Ecology, 89, 2290-2301.

Ward P.S. (2010) Taxonomy, phylogenetics, and evolution. Ant Ecology (ed. by L. Lach, C. Parr, and K.L. Abbot), pp. 402. Oxford University Press, Oxford.

Wardle D.A., Hyodo F., Bardgett R.D., Yeates G.W., \& Nilsson M.-C. (2011) Long-term aboveground and belowground consequences of red wood ant exclusion in boreal forest. Ecology, 92, 645-656.

Way M.J. (1963) Mutualism Between Ants and Honeydew-Producing Homoptera. Annual Review of Entomology, 8, 307-344.

Webb C.O., Ackerly D.D., McPeek M.A., \& Donoghue M.J. (2002) Phylogenies and Community Ecology. Annual Review of Ecology and Systematics, 33, 475-505.

Wiken E., Jimenez-Nava F., \& Griffith G. (2011) North American Terrestrial Ecoregions. Level III. Commission for Environmental Cooperation, Montreal, Canada. 149p.

Williams J.W. \& Jackson S.T. (2007) Novel climates, no-analog communities, and ecological surprises. Frontiers in Ecology and the Environment, 5, 475-482. 
Wittman S.E. \& Gotelli N.J. (2011) Predicting community structure of ground-foraging ant assemblages with Markov models of behavioral dominance. Oecologia, 166, 207-219.

\section{Biosketches:}

I. Del Toro is an NSF Postdoctoral Fellow working on arthropod biodiversity along environmental gradients and political boundaries, he is specifically interested in how climate change and different management strategies impact the conservation of various arthropodmediated ecosystem services and processes. R. Silva's research interests include taxonomy and diversity of Neotropical ants. He is particularly interested in the functional ecology of ant communities in tropical ecosystems, based on morphological traits. A.M. Ellison is a Senior Research Fellow at Harvard University. He studies the dissolution and reorganization of ecological assemblages following acute and chronic disturbances.

\section{Supplementary Material:}

S1: Species by trait data matrix

S2: Functional group cluster dendrogram

S3: Natural history collections list and number of unique species records

S4: A) AUC values for each distribution model. Blue points show Maxent, black points show BRT, green points show GAM, and red point show GLM AUC values for all 70 species. B) Histogram of the distribution of unique point localities used to build the SDMs for each of the 70 species considered in this study.

S5: Detailed outputs of distributions of the ten functional groups for the 2050 and 2070 climate scenarios. 
Tables and Figure Captions:

Table 1 summarizes the traits which helped cluster functional groups, as well as the main functional processes mediated by species in any given group.

\begin{tabular}{|c|c|c|}
\hline Group & Description & Primary Functional Role \\
\hline 1 & $\begin{array}{l}\text { medium body sized, soil dwelling, omnivorous, warm } \\
\text { climate and widespread, open and sandy habitat } \\
\text { Formicinae species }\end{array}$ & Soil movers \\
\hline 2 & $\begin{array}{l}\text { large body sized, omnivorous, wood dwelling, forest and } \\
\text { edge Camponotus species }\end{array}$ & Wood decomposers \\
\hline 3 & $\begin{array}{l}\text { medium body sized, omnivores, grass and soil dwelling, } \\
\text { widespread, edge and forest habitat Dolichoderinae. }\end{array}$ & $\begin{array}{l}\text { Invertebrate community } \\
\text { regulators }\end{array}$ \\
\hline 4 & $\begin{array}{l}\text { large body sized, omnivores, soil dwelling, social } \\
\text { parasitic, dominant, forest and edge Formica species }\end{array}$ & Ant community regulators \\
\hline 5 & $\begin{array}{l}\text { large body sized, medium sized colonies, omnivores, } \\
\text { submissive forest and edge Formica species }\end{array}$ & Soil movers \\
\hline 6 & $\begin{array}{l}\text { large body sized, omnivores, soil dwelling, non-parasitic, } \\
\text { dominant Formica species }\end{array}$ & Soil movers \\
\hline 7 & $\begin{array}{l}\text { medium to large body sized, omnivorous, seed } \\
\text { dispersing, forest and edge habitat, Myrmicinae (some } \\
\text { are behaviorally dominant) }\end{array}$ & Seed dispersers \\
\hline 8 & $\begin{array}{l}\text { medium body sized, omnivores, soil dwelling, warm } \\
\text { climate/widespread, forest habitat, Myrmicinae }\end{array}$ & Decomposers \\
\hline 9 & $\begin{array}{l}\text { small body sized, small colonies, omnivores, soil } \\
\text { dwelling, warm climate/widespread, open habitat, } \\
\text { Myrmicinae }\end{array}$ & Decomposers \\
\hline 10 & $\begin{array}{l}\text { small body sized, small colonies, predators, warm } \\
\text { climate/widespread, often litter species }\end{array}$ & $\begin{array}{l}\text { Invertebrate community } \\
\text { regulators }\end{array}$ \\
\hline
\end{tabular}

Table 2: Percentage of sites predicted to have changes in species and functional group richness.

\begin{tabular}{|l|l|l|l|l|}
\hline & RCP 2.6 & RCP. 4.5 & RCP 6.0 & RCP 8.5 \\
\hline $\begin{array}{l}\text { predicted species } \\
\text { richness declines }\end{array}$ & $51 \%$ & $74 \%$ & $62 \%$ & $87 \%$ \\
\hline $\begin{array}{l}\text { predicted species } \\
\text { richness } \\
\text { increases }\end{array}$ & $42 \%$ & $22 \%$ & $34 \%$ & $12 \%$ \\
\hline
\end{tabular}




\begin{tabular}{|l|l|l|l|l|}
\hline $\begin{array}{l}<5 \% \text { predicted } \\
\text { change in } \\
\text { species richness }\end{array}$ & $7 \%$ & $4 \%$ & $4 \%$ & $1 \%$ \\
\hline $\begin{array}{l}\text { predicted } \\
\text { functional group } \\
\text { richness declines }\end{array}$ & $25 \%$ & $18 \%$ & $45 \%$ & $69 \%$ \\
\hline $\begin{array}{l}\text { predicted } \\
\text { functional group } \\
\text { richness } \\
\text { increases }\end{array}$ & $8 \%$ & $7 \%$ & $7 \%$ & $7 \%$ \\
\hline $\begin{array}{l}<5 \% \text { predicted } \\
\text { change in } \\
\text { functional group } \\
\text { richness }\end{array}$ & $67 \%$ & $75 \%$ & $48 \%$ & $24 \%$ \\
\hline
\end{tabular}



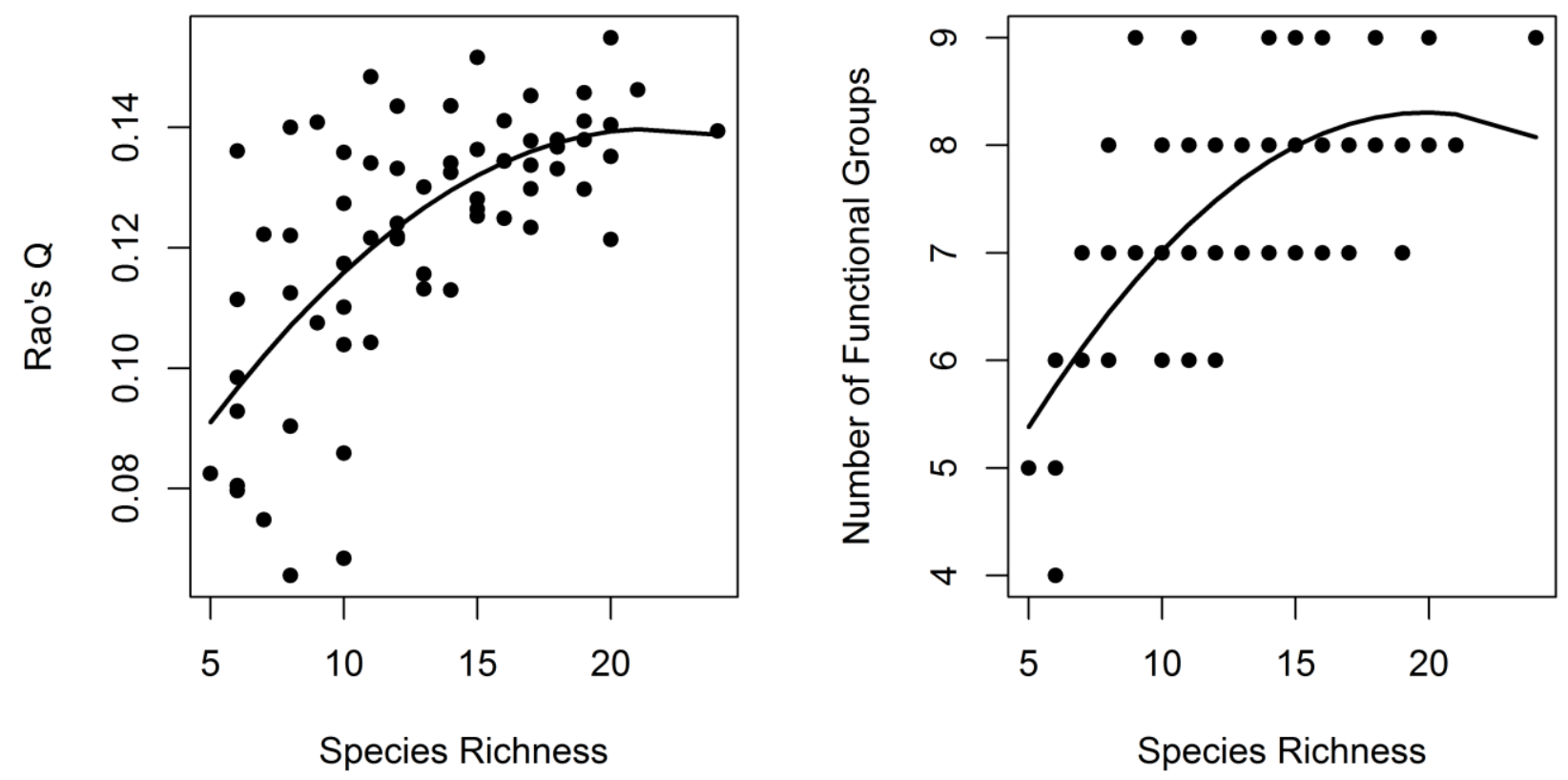

Figure 1: A) relationship between observed species richness and functional diversity (Rao's Q) at each sampling site. B) Relationship between observed species richness and the number of functional groups at each sampling site. Solid line is the best fit quadratic regression. 

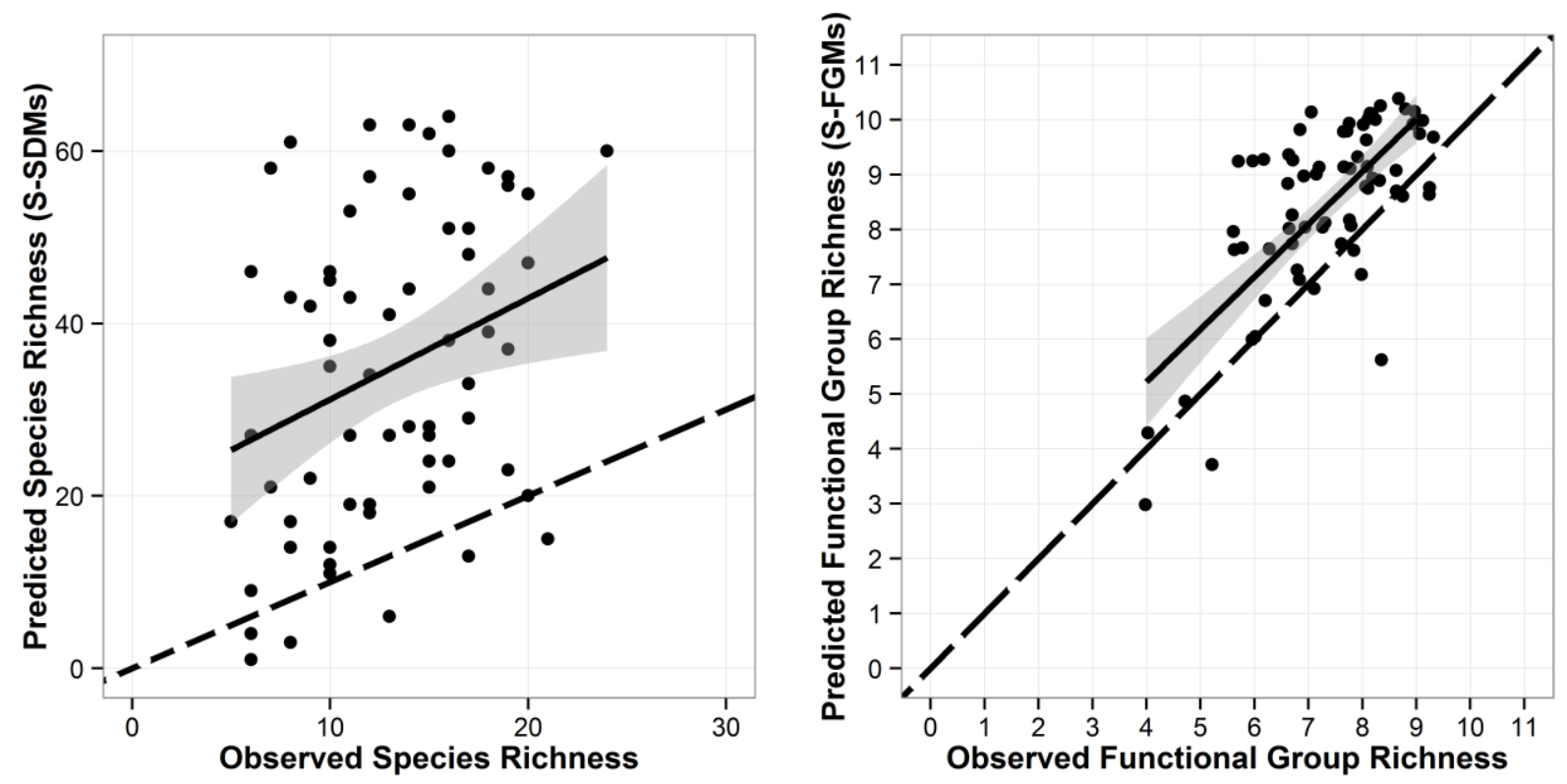

Figure 2: A) relationship between observed species richness and predicted species richness from S-SDMs at each sampling site. B) Relationship between observed number of functional groups and the predicted number of functional groups from S-FGMs at each sampling site. Dashed lines show the 1:1 relationship between the $\mathrm{x}$ and $\mathrm{y}$ axes. The black lines show the best fit linear regression with the $95 \%$ confidence intervals shaded grey. 


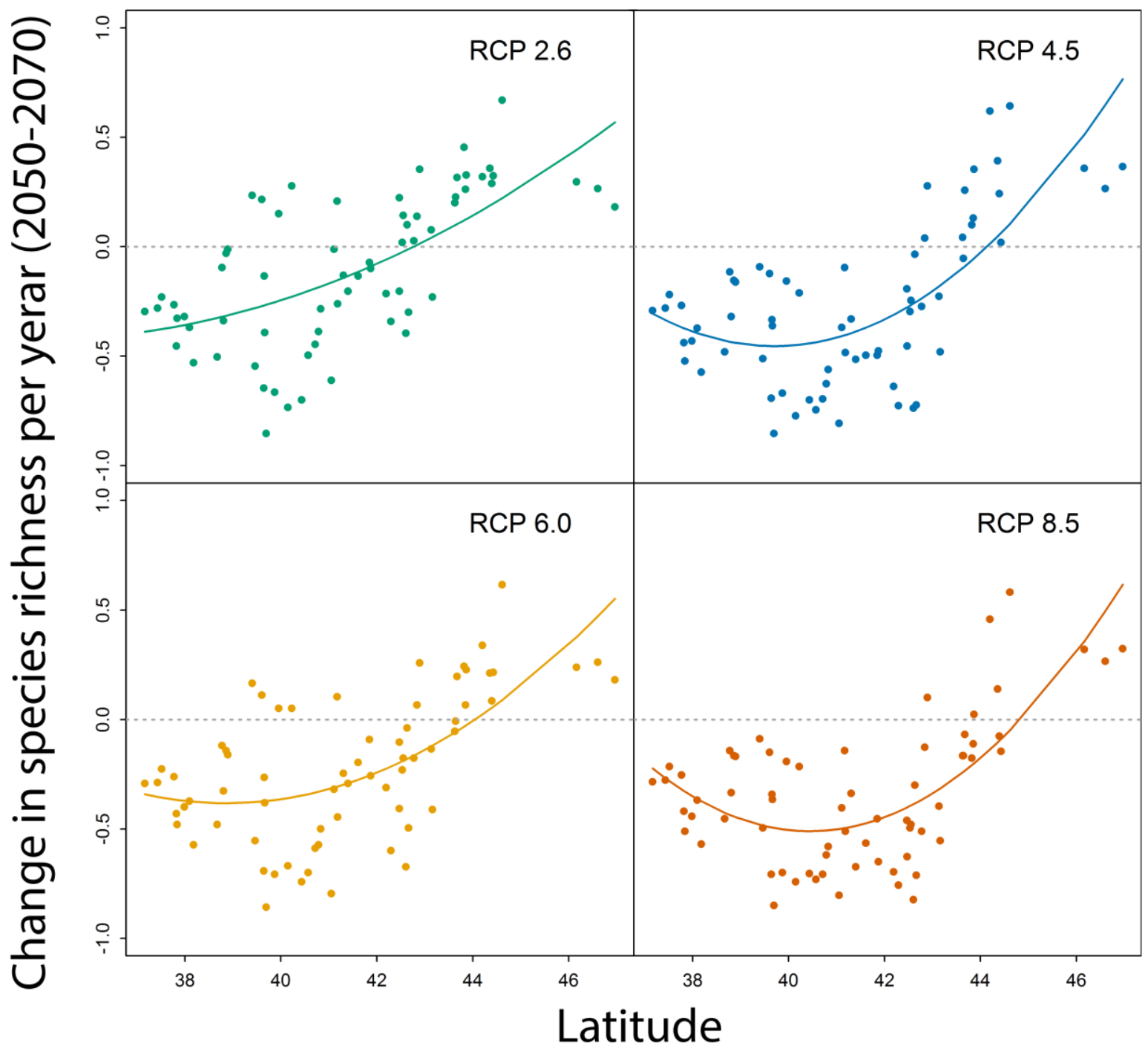

Figure 3: Predicted changes in species richness at 67 sites using four climate scenarios (RCP 2.6, 4.5, 6.0 and 8.5). Sites below the zero (dashed) line, are sites where species loss is predicted to be greater than species gain (i.e. the richness vs. time regression coefficient $<0$ ). Sites above the zero line, are sites where species gain is predicted to be greater than species lost (i.e. the richness vs. time regression coefficient $>0$ ). 


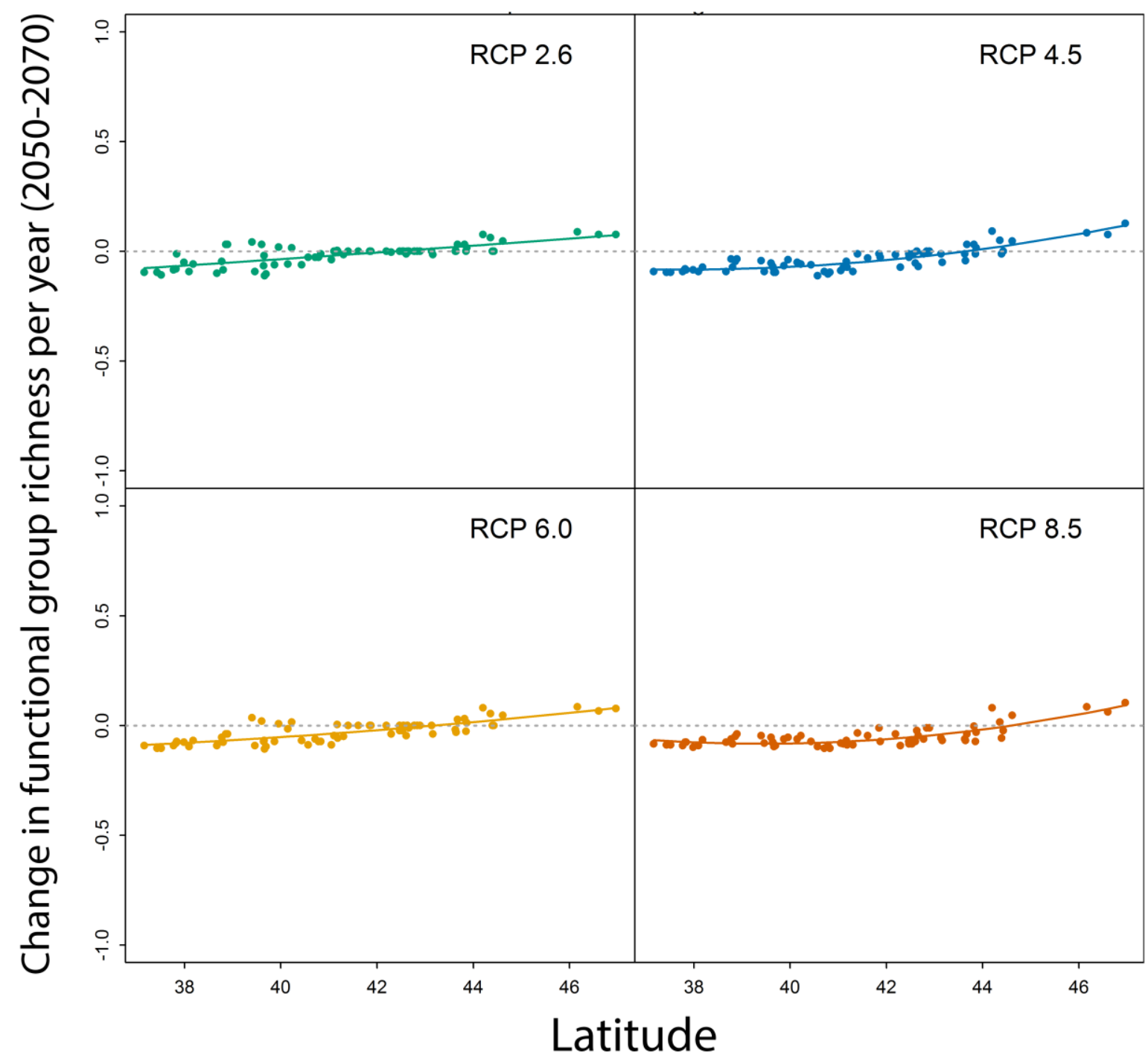

Figure 4: Predicted changes in functional group richness at 67 sites using four climate scenarios (RCP 2.6, 4.5, 6.0 and 8.5). Sites below the zero (dashed) line, are sites where functional group loss is predicted to be greater than functional group gain (i.e. the functional group richness vs. time regression coefficient $<0$ ). Sites above the zero line, are sites where functional group gain is predicted to be greater than functional group lost (i.e. the functional group richness vs. time regression coefficient $>0$ ). 

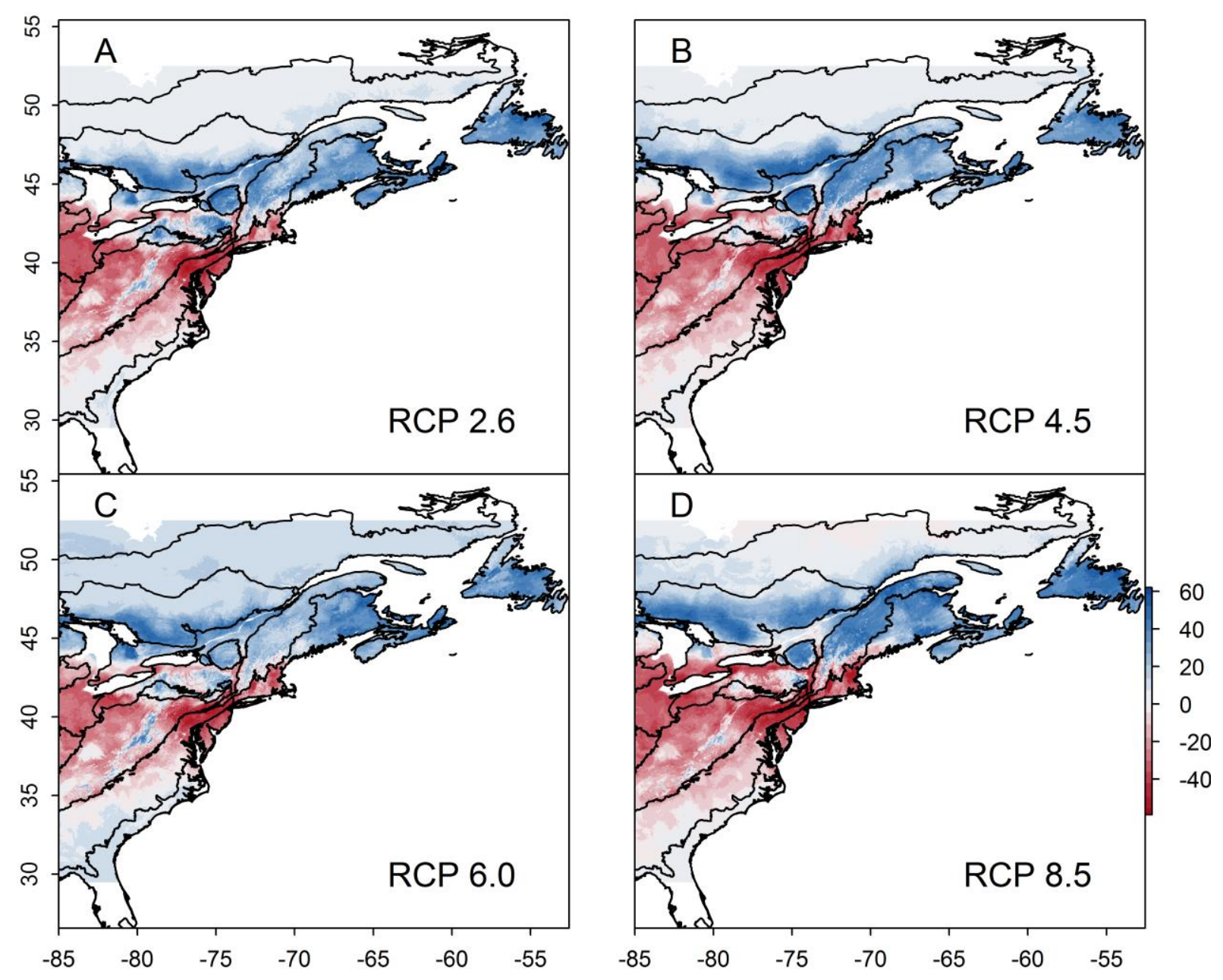

Figure 5: Predicted regional richness changes in 2050 using four climate scenarios. A) RCP 2.6

B) RCP 4.5 C) RCP 6.0 D) RCP 8.5 

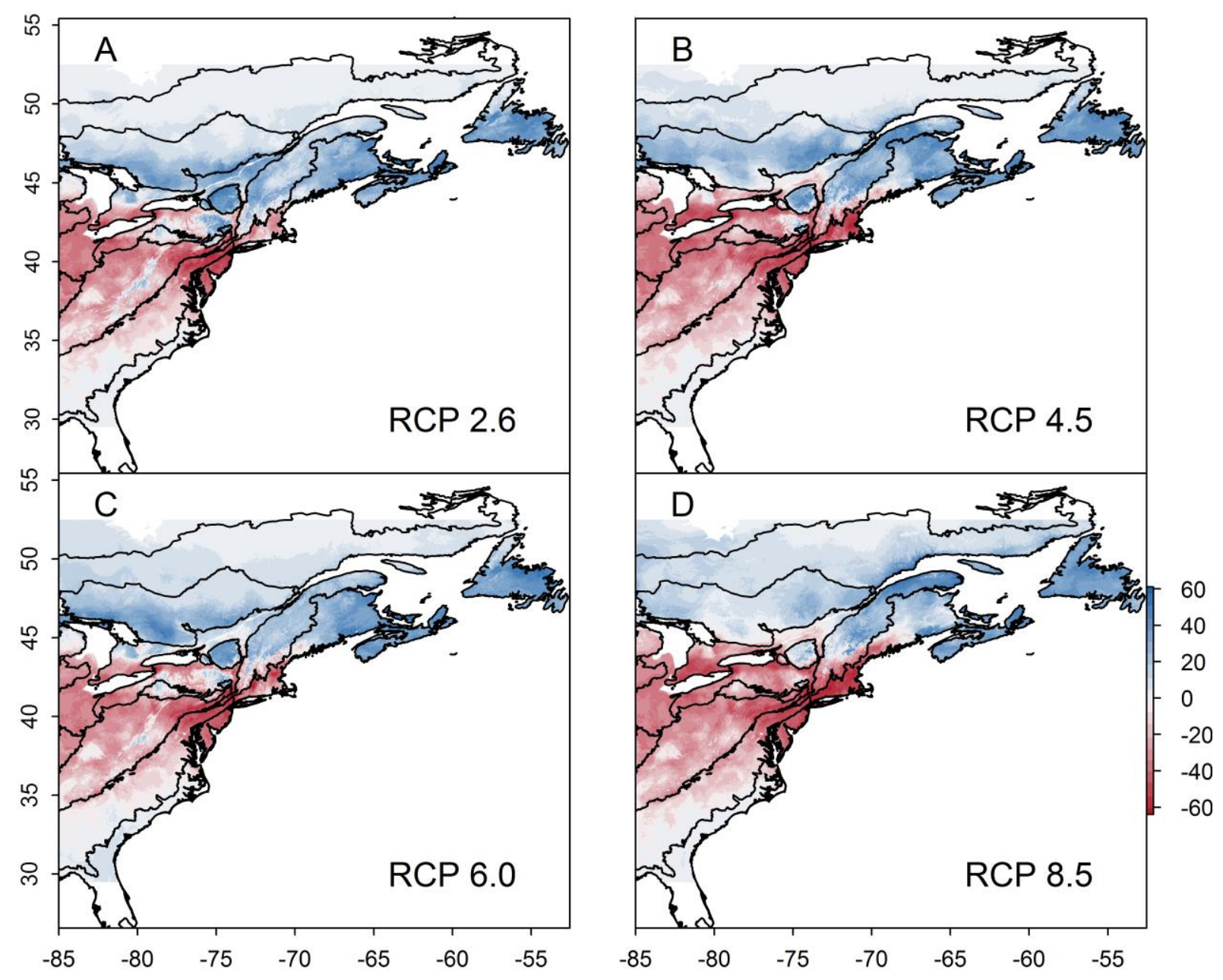

Figure 6: Predicted regional richness changes in 2070 using four climate scenarios. A) RCP 2.6

B) RCP 4.5 C) RCP 6.0 D) RCP 8.5 

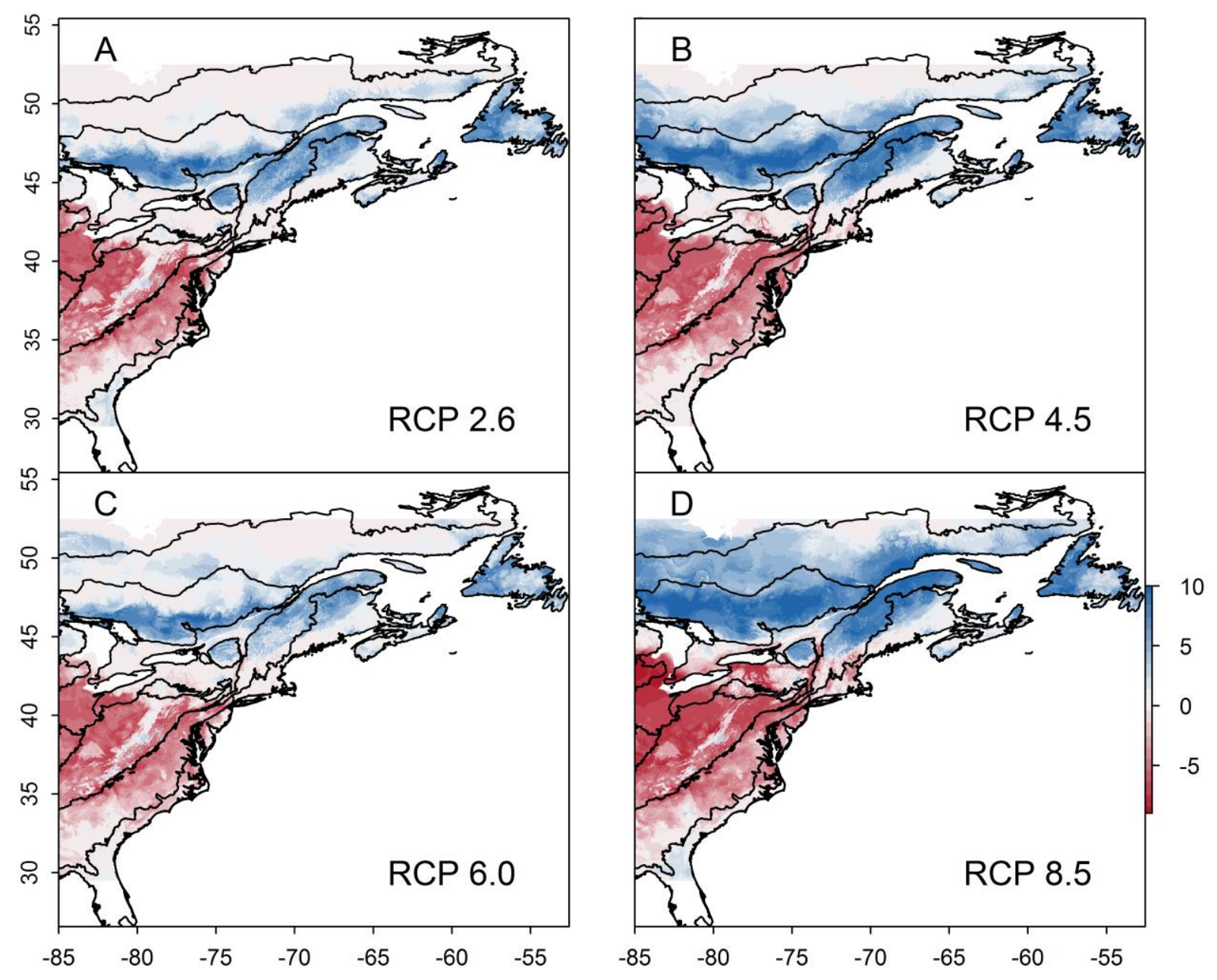

Figure 7: Predicted functional group richness changes in 2050 using four climate scenarios. A) RCP 2.6 B) RCP 4.5 C) RCP 6.0 D) RCP 8.5 

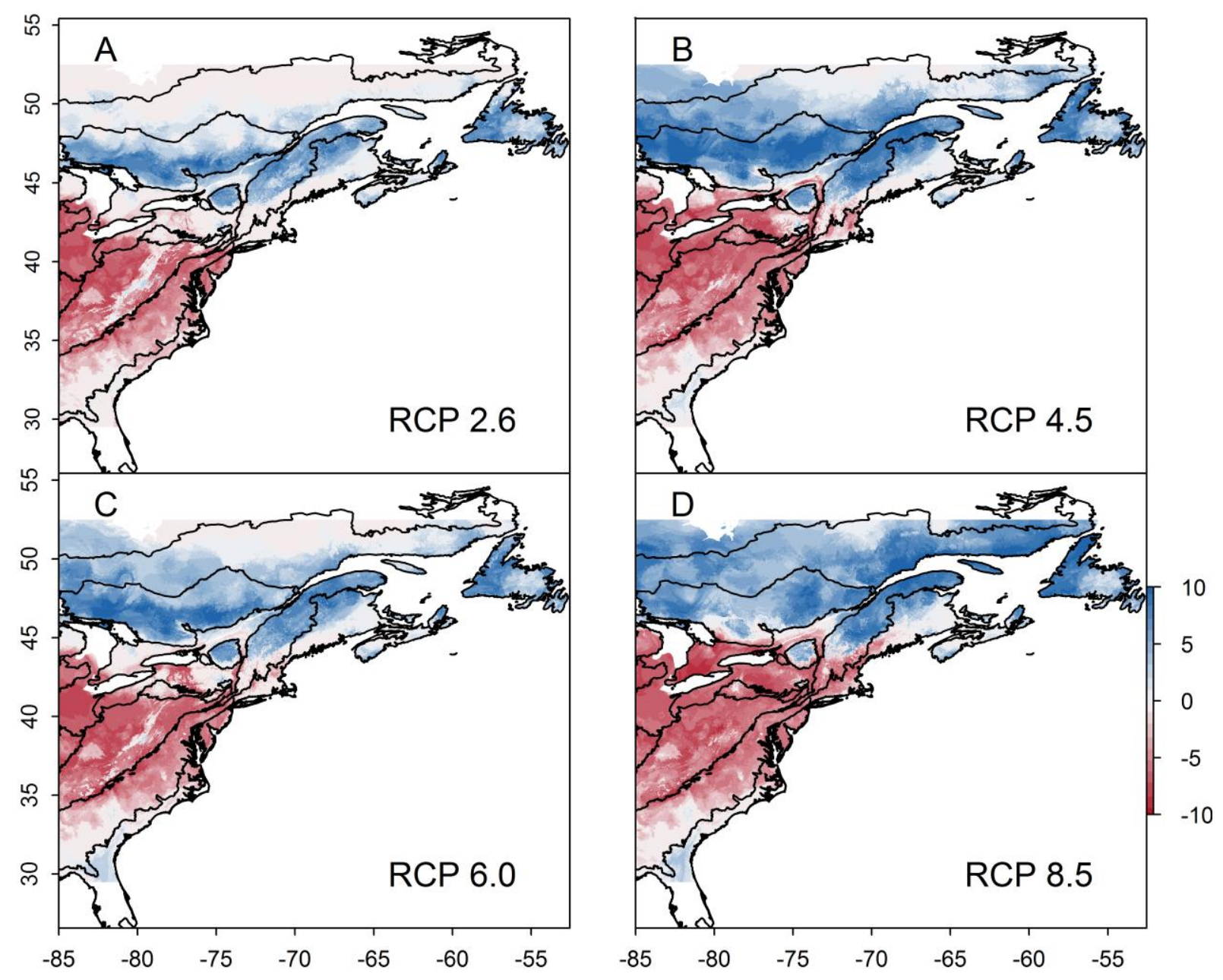

Figure 8: Predicted functional group richness changes in 2070 using four climate scenarios. A) RCP 2.6 B) RCP 4.5 C) RCP 6.0 D) RCP 8.5 


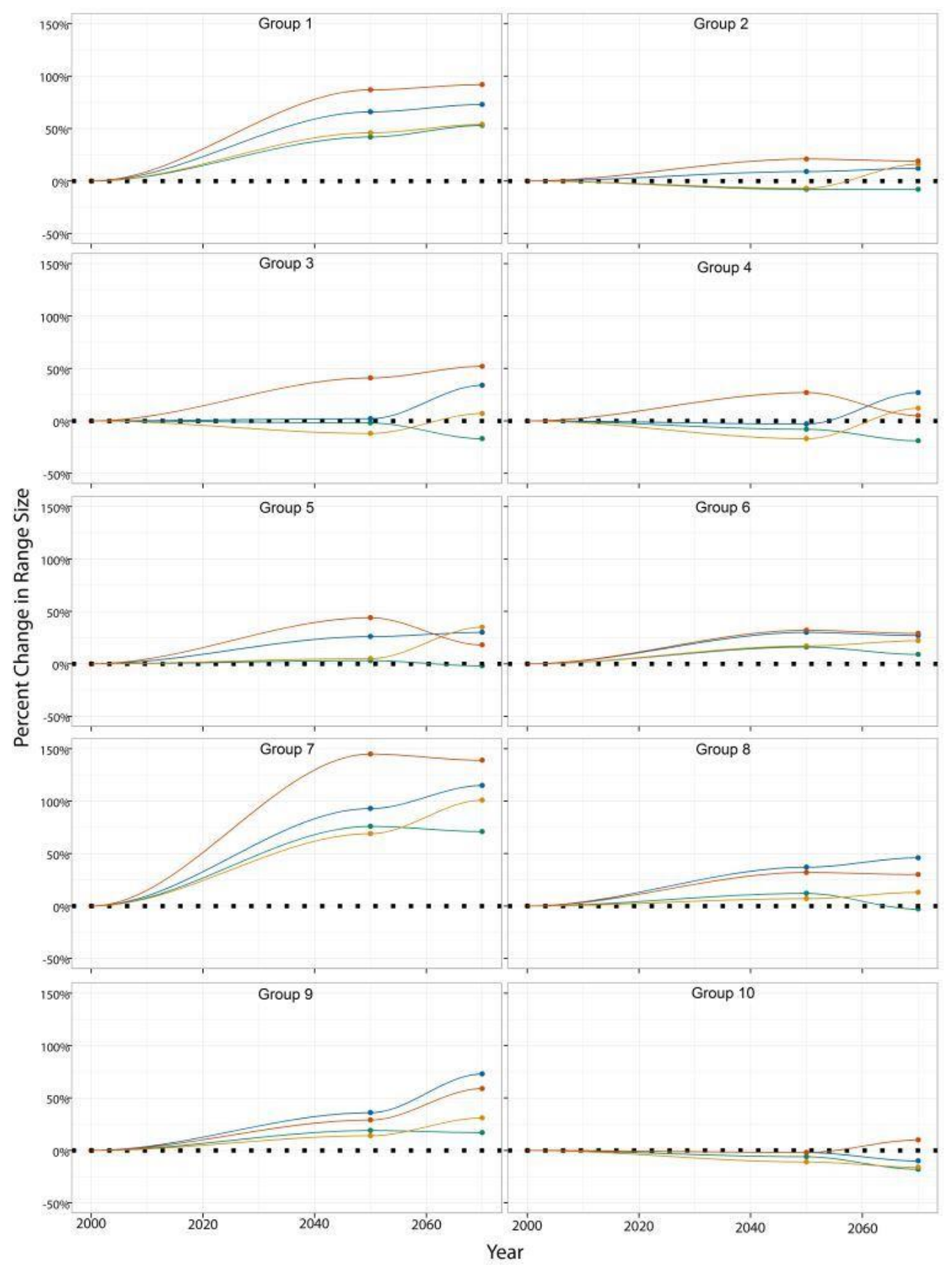

Figure 9: Percent change in range size subdivided by functional groups between the years 200 and 2070. Green lines represent RCP 2.6 blue lines represent RCP 4.5, yellow lines represent RCP 6.0 and red lines represent RCP 8.5. 